УДК 621.43

РАЗРАБОТКА МЕТОДА СИНТЕЗА ПОЛИФУНКЦИОНАЛЬНОЙ ПРИСАДКИ К ДИЗЕЛЬНОМУ ТОПЛИВУ НА ОСНОВЕ ПРОИЗВОДНЫХ КАРБОНОВЫХ КИСЛОТ И ИССЛЕДОВАНИЕ ЭФФЕКТИВНОСТИ ЕЕ ДЕЙСТВИЯ

\title{
DEVELOPMENT OF A METHOD FOR SYNTHESIS \\ OF A POLYFUNCTIONAL ADDITIVE TO DIESEL FUEL BASED ON CARBONIC ACID DERIVATIVES AND STUDY OF THE EFFICIENCY OF ITS ACTION
}

А.Ф. Ахметов, Л.М. Халилов, О.А. Баулин, К.С. Нелькенбаум, С.Я. Нелькенбаум

Уфимский государственный нефтяной технический университет, Институт нефтехимии и катализа Российской академии наук, ООО Синтез ТНП, г. Уфа, Российская Федерация

Arslan F. Akhmetov, Leonard M. Khalilov, Oleg A. Baulin, Konstantin S. Nelkenbaum, Savely Ya. Nelkenbaum

Ufa State Petroleum Technological University, Institute of Petrochemistry and Catalysis of Russian Academy of Sciences, Sintez TNP LLC, Ufa, Russian Federation e-mail: fox@web-rb.ru

Аннотация. Одним из основных источников загрязнения атмосферы являются выбросы автомобильных двигателей, работающих на органических топливах. Вместе с тем, с начала внедрения в конце прошлого века топлива класса 1 и 2 со сверхнизким содержанием серы возросло число 
проблем и отказов топливных насосов высокого давления. Смазывающая способность дизельных топлив зависит в значительной мере от полярных соединений (гетероциклические ароматические соединения, соединения азота и кислорода), образующих защитный слой на поверхности металла. В процессе гидроочистки данные соединения удаляются из дизельного топлива. Одним из способов решения проблем является полное изменение системы подачи и впрыска топлива, применения материалов, не требующих смазки. Данный путь требует больших денежных затрат и не решает проблему для уже выпущенных и работающих дизельных двигателей. Таким образом, единственным способом для решения выше обозначенной задачи является повышения смазывающей способности топлива путем добавления смазывающих присадок.

Авторами разработан удобный метод синтеза полифункциональной присадки на основе сложных эфиров дистиллированного таллового масла и жирных кислот растительного масла этиленгликолем с применением вакуумного насоса и последующим вовлечением непрореагировавших в реакцию этерификации жирных кислот дистиллированного таллового масла и жирных кислот растительного масла с амидо-имидазолиновыми добавками для придания присадке противоокислительных свойств.

Abstract. One of the main sources of air pollution is emissions from motor vehicles running on fossil fuels. However, since the introduction at the end of the last century of class 1 and 2 ultra-low sulfur fuels, the number of problems and failures of high pressure fuel pumps has increased. The lubricity of diesel fuels depends to a large extent on polar compounds (heterocyclic aromatic compounds, nitrogen and oxygen compounds) that form a protective layer on the metal surface. During the hydrotreating process, these compounds are removed from the diesel fuel. One way to solve the problem is to completely change the fuel supply and injection system, using materials that do not require lubrication. This way requires a lot of money and does not solve the problem for already produced and operating 
diesel engines. Thus, the only way to solve the above problem is to increase the lubricity of the fuel by adding lubricating additives.

The authors have developed a convenient method for the synthesis of a polyfunctional additive based on esters of distilled tall oil and fatty acids of vegetable oil with ethylene glycol using a vacuum pump and the subsequent involvement of unreacted fatty acids of distilled tall oil and fatty acids of vegetable oil with amido-imidazoline additives in the esterification reaction to impart anti-imidazoline additives to the additive. properties.

Ключевые слова: автомобильные двигатели; органическое топливо; смазывающие присадки; дистиллированное талловое масло; жирные кислоты растительного масла; этиленгликоль

Keywords: car engines; fossil fuels; lubricating additives; distilled tall oil; fatty acids of vegetable oil; ethylene glycol

Одним из основных источников загрязнения атмосферы являются выбросы автомобильных двигателей, работающих на органических топливах. Начиная с 2000 г., резко возросли экологические требования к автомобильным топливам. Так, для дизельных топлив цетановое число должно быть не менее 51, содержание серы - не более 350 ррм (с 2000 г.), 50 ррм (с 2005 г.) и 10 ррм (с 2009 г.), полициклических ароматических углеводородов - не более 8 \% масс. (с 2009 г.). Для дизельных топлив, поставляемых за рубеж, предъявляются дополнительные требования по качеству - предельная температура фильтруемости, скорректированный диаметр пятна износа.

Действующие ранее в Российской Федерации нормативы на дизельные топлива сильно отличались от стандартов Европейского союза.

В 2011 г. утвержден Технический Регламент Таможенного союза ТР ТС 013/2011 «О требованиях к автомобильному и авиационному бензину, 
дизельному и судовому топливу, топливу для реактивных двигателей и мазуту» (с изменениями от 19 декабря 2019 г.).

Вместе с тем, с начала внедрения в конце прошлого века топлива класса 1 и 2 со сверхнизким содержанием серы $(<20$ ppm) возросло число проблем и отказов топливных насосов высокого давления (ТНВД). Если у топлив с содержанием серы в количестве 2000 ppm ресурс насосов высокого давления составлял 200 тыс. км пробега (и более), то при снижении серы до 10 ppm. peсурс насосов ТНВД снижался в 20 раз (10 тыс. км). Также эксплуатация двигателя на дизельном топливе с недостаточной смазкой приводит к изменениям смешивания топлива из-за падения давления впрыска топлива. Как следствие, возникают отклонения, связанные со своевременной подачей топлива, воспламенением и сгоранием, приводящие к значительной потере мощности двигателя. Из-за нарушения параметров впрыска топлива сокращается срок эксплуатации дизельных форсунок и распылителей. Срок службы распылителей по ГОСТ 10579-88 (с изменениями от 1995 г.) «Форсунки дизелей. Общие технические условия» должен быть не менее 0,5 peсурса двигателя, форсунок автомобильных двигателей не менее 3500 ч. Согласно исследованию А.П. Быченина [1], при эксплуатации двигателя 4ЧН 15/20,5 на дизельном топливе с низким содержанием серы срок службы системы впрыска топлива не превышает 1200-1300 ч, для двигателя 8ЧН13 -1400-1500 ч, срок службы плунжерных пар не превышают 2000-2500 рабочих часов [1].

В исследованиях [2, 3] установлено, что смазывающая способность дизельных топлив зависит не только от содержания сераорганических соединений (сульфиды, дисульфиды, бензтиофены), а в значительной мере от полярных соединений (гетероциклические ароматические соединения, соединения азота и кислорода), образующих защитный слой на поверхности металла. В процессе гидроочистки данные соединения также удаляются из дизельного топлива. 
Одним из способов решения проблем является полное изменение системы подачи и впрыска топлива, применения материалов, не требующих смазки. Данный путь требует больших денежных затрат и не решает проблему для уже выпущенных и работающих дизельных двигателей. Таким образом, единственным способом для решения выше обозначенной задачи является повышения смазывающей способности топлива путем добавления смазывающих присадок.

Смазывающие присадки представляют собой поверхностно-активные вещества, способные к образованию на поверхности металла тонкого адсорбционного разделительного слоя. Адсорбционный слой способен изменять характеристики поверхностей путем изменения межмолекулярного взаимодействия между двумя контактирующими металлами, что способствует существенному уменьшению силы трения между ними. Как правило, смазывающие присадки имеют небольшую полярную группу, которая прикрепляется к поверхности металла и достаточно длинную неполярную углеводородную группу.

Присадки, представленные на отечественном и зарубежном рынке, условно можно разделить на 2 большие группьл.

I. Жирные кислоты талловых масел, получаемые во время варки древесины в сульфатном варочном процессе, при котором под действием гидроксида натрия и сульфида натрия смоляные и жирные кислоты омыляются в виде натриевых солей. После разложения сульфатного мыла получается сырое талловое масло, которое разделяют при помощи ректификация на следующие продукты:

1. талловые жирные кислоты (ЖКТМ) (чистота 93-97 \%), наблюдаются примеси смоляных и нейтральных веществ;

2. талловая канифоль (талловые смоляные кислоты, чистота 80-95 \%);

3. дистиллированное талловое масло (ДТМ) - продукт перегонки, который содержит смоляные и нейтральные вещества; 
4. легкое талловое масло (ЛТМ) - начальная фракция разгонки (нейтральные летучие вещества и летучие жирные кислоты, главным образом, пальмитиновая);

5. талловый пек - остаток от дистилляции ТМ, содержит нейтральные вещества, димеры жирных кислот, сложные эфиры кислот, лактоны, оксикислоты. Все эти вещества имеют высокие температуры кипения и плавления.

II. Сложные эфиры жирных кислот растительных масел (рапсового, подсолнечного), которые имеют ряд существенных недостатков: значительное повышение вязкости топлива, что делает нецелесообразным его использование в условиях низкой температуры, окислительная нестабильность и образование отложений в камерах сгорания двигателя, приводящих к коррозии и уменьшению мощности двигателя.

Кроме практических аспектов применения присадок на основе растительных масел необходимо также учитывать, что растительные масла широко используются в питании человека, а расширенное применение масел как сырья для синтеза может повлиять на повышения цен на продукты питания. Таким образом, развитие этой области должно учитывать не только технические аспекты, но и их влияние на экономические и социальные аспекты.

В мировой патентной литературе описано большое количество разнообразных смазывающих присадок.

В патенте США № US3279881B2 (Caprotti Brid Dilwortho, 1998 г.) описана смазывающая добавка - многоосновная кислота, или сложный эфир многоосновной кислоты с одноатомными спиртами $\mathrm{C}_{1}-\mathrm{C}_{5}$ с неполным эфиром многоатомного спирта и жирной кислоты (глицерин моноолеат, сорбитанмоноолеат или пентаэритритолмоноолеат).

В патенте США № US5833722A (Brian William, Davies Rinaldo, Caprotti Brid Dilwortho, 1998 г.) описано использование азотсодержащих соединений 
как продуктов реакции амина и карбоновой кислоты в смеси с эфиром многоатомного спирта и карбоновой кислоты.

В патенте США № US6328771B1 (David J. Moreton, 1998 г.) описываются улучшающие смазывающие способности топлива композиции, синтезируемые по реакции карбоновых кислот с гетероциклическим ароматическим амином.

К сожалению, в настоящие время основу российского рынка присадок составляют импортные присадки, а собственное производство практически отсутствует.

В этой связи разработка новых полифункциональных присадок для улучшения смазывающих, седиментационных и антиокислительных свойств дизельных топлив на основе производных карбоновых кислот является актуальной задачей нефтехимической промышленности.

Для решения поставленной задачи необходимо осуществить синтез сложных эфиров карбоновых кислот С18-C22 подсолнечного масла (таллового масла) путем этерификации этиленгликолем с последующим вовлечением не вступивших в реакцию этерификации карбоновых кислот в синтез целевых амидов, провести исследование разработанной присадки на смазывающие, седиментационные свойства гидроочищенных дизельных топлив, а также разработать технологию получения полифункциональной присадки для улучшения смазывающих, седиментационных и антиокислительных свойств дизельных топлив на основе производных карбоновых кислот.

В качестве базового объекта исследования выбрана гидроочищенная дизельная фракция (производство АО «ТАИФ НК»). В качестве сырья для получения полифункциональной присадки использовали: подсолнечное масло, получаемое по ТУ 9145-006-29590956-10; дистиллированное масло по ТУ 13-00281074-26-95; этиленгликоль по ГОСТ 19710-83; смесь этаноламинов АMИХ-1000 (производство BASF, Германия). 
Выбор жирных кислот для синтеза присадок осуществлен на основе анализа отечественного рынка источника жирных кислот. Существуют природные источники жирных кислот, выделяемых из триглицеридов растительного масла и из животных жиров. Значительная часть зарубежных производств использует синтетические жирные кислоты, получаемые окислением парафинов на марганцевом катализаторе. В Российской Федерации синтетические жирные кислоты производились на заводе ОАО «Уфанефтехим» вплоть до 2000 г., однако в настоящее время производство закрыто, что сильно затрудняет возможности использования синтетических жирных кислот для получения необходимых современных присадок.

Для синтеза сложного эфира выбран коммерчески доступный продукт жирные кислоты растительного масла (ЖКРМ) производства ООО «СтокМет» по ТУ 9145-006-29590956-10 и дистиллированное таловое масло (ДТМ) - кубовый остаток разгонки сырого талового масла, состоящий в основном из линолевой кислоты производства Братского целлюлознобумажного комбината по ТУ 13-00281074-26-95.

Амидированием жирных кислот, не вступивших в реакцию этерификации, получены амидо-имидазолины для придания антиокислительных свойств синтезированному сложному эфиру и для улучшения седиментационной устойчивости дизельного топлива.

Первая стадия образования амида проходит при температуре 130-160 들 вторая стадия образования имидазолина - при температуре 160 $220{ }^{\circ} \mathrm{C}$. Реакция протекает с выделением воды, которая отводится вакуумированием из реакционной смеси для смещения направления реакции в сторону образования целевого продукта.

Важной особенностью процесса этерификации является выбор используемого спирта, от которого зависит температура проведения реакции. Традиционное использование этанола и метанола позволяют вести процесс в диапазоне $70-80$ $\mathrm{C}$, то есть при достаточно низких температурах кипения данных спиртов. Вместе с тем, следует отметить, что для работы с 
метанолом требуется специальное разрешение, а этанол также является строго учетным продуктом, для которого требуется отдельное разрешение и подключение к единой государственной автоматизированной информационной системе, предназначенной для государственного контроля над объёмом производства и оборота этилового спирта. Все перечисленные мероприятия значительно увеличивают расходы на администрирование при использовании метилового и этилового спиртов.

Бутиловый и изопропиловый спирты, несмотря на доступность, имеют ограниченный объем производства, а также высокую стоимость. В литературе отсутствует упоминание об этерификации жирных кислот с использованием многоатомных спиртов. Типичным двухатомным спиртом является этиленгликоль. Он имеет температуру кипения 197,3 С, что позволяет проводить синтез сложного эфира при указанной температуре. Этиленгликоль коммерчески доступен, и для работы с ним не требуется специального разрешения.

Для получения сложных эфиров были использованы следующие кислотные катализаторы:

- серная кислота (ГОСТ 4204-77);

- соляная кислота (ГОСТ 3118-77);

- катионит КУ-2-8 (по ТУ).

Катионит КУ-2-8 представляет из себя сульфонированный сополимер стирола - дидивинилбензола. Обычно сульфированные ионообменные смолы получают в виде зёрен диаметром 0,3-1,5 мм. Носителями каталитической активности сульфокатионитов являются SO3H-группы, способные обмениваться протонами с катионами раствора. Максимальная рабочая температура сульфокатионитов достигает $120-150{ }^{\circ} \mathrm{C}$.

Применение КУ-2-8 (2,5 \% масс.) увеличивает скорость реакции на $15 \%$. Использование с технологической точки зрения в качестве катализатора КУ-2-8 менее предпочтительно по сравнению с соляно-серными 
катализаторами, поскольку требует дополнительной стадии выделения катионита КУ-2-8 из реакционной массы.

Синтез сложного эфира осуществляли в трехгорлой колбе с перемешивающим устройством с системой удаления водных паров, состоящей из холодильника и вакуумного насоса. Нагрев осуществляли в колбонагревателе LH-120, контроль температуры осуществляли с помощью ртутного термометра.

Поскольку используемый диатомный спирт позволяет вести синтез при температуре кипения выше $100{ }^{\circ} \mathrm{C}$, то применение вакуумного насоса позволяет исключить необходимость стадии отчистки после синтеза продукта, что, в свою очередь, позволяет существенно удешевить процесс и уменьшить его продолжительность.

По окончанию синтеза реакционную массу охлаждали до $100{ }^{\circ} \mathrm{C}$ и добавляли смесь этиленаминов АMИХ 1000 (производство BASF) для синтеза амидо-имидазолина из жирных кислот, не вступивших в реакцию с этиленгликолем. Внедрение второй стадии синтеза наряду с применением гомогенного кислотного катализатора позволило, помимо придания противоокислительных свойств сложному эфиру, избавиться от необходимости очистки конечного продукта от использованного катализатора.

Установлено, что оптимальным является использование в качестве катализатора серной кислоты в дозировке 2 \%, поскольку повышение концентрации до 5 \% приводит к деградации спирта и повышению кислотности у конечного продукта. Суммарный выход эфиров ЖКРМ составил 71,23 \%, выход эфиров ДТМ составил 80,25 \% масс.

Результаты изучения состава сложных эфиров и продуктов их реакций с амином подтверждают синтез полифункциональной присадки, содержащей в своем составе азотистые группы, являющиеся противоокислительным и диспергирующим компонентом разрабатываемой присадки. 
По результатам исследования влияния на смазывающую способность дизельного топлива с синтезированной присадкой при концентрации от $0,5 \%$ до $1,5 \%$ отмечено значительное уменьшение диаметра пятна износа. Дизельное топливо с полифункциональной присадкой во всех концентрациях достигло требования ГОСТ по показателю «Смазывающая способность» (таблица 1).

Таблица 1. Результаты исследования влияния на смазывающую способность дизельного топлива с синтезированной присадкой при концентрации от $0,5 \%, 1,0 \%$ и $1,5 \%$

\begin{tabular}{|c|c|c|c|c|c|}
\hline Свойство & $\begin{array}{c}\text { Единица } \\
\text { измерения }\end{array}$ & $\begin{array}{c}\text { Без } \\
\text { присадки }\end{array}$ & $0,5 \%$ & $1,0 \%$ & $1,5 \%$ \\
\hline Плотность при $20^{\circ} \mathrm{C}$ & $\kappa \Gamma / \mathrm{M}^{3}$ & 845 & 846 & 849 & 853 \\
\hline $\begin{array}{l}\text { Кинематическая } \\
\text { вязкость при } 40^{\circ} \mathrm{C}\end{array}$ & $\mathrm{MM}^{2} / \mathrm{c}$ & 2,70 & 2,72 & 2,75 & 2,80 \\
\hline Йодное число & $\Gamma \mathrm{I}_{2} / 100 \Gamma$ & 0,26 & 0,46 & 0,88 & 1,20 \\
\hline Кислотное число & $\begin{array}{c}\text { Мг } \\
\mathrm{KOH} / 100 \text { г. }\end{array}$ & 0,22 & 0,39 & 0,66 & 0,88 \\
\hline $\begin{array}{l}\text { Температура } \\
\text { застывания }\end{array}$ & ${ }^{\circ} \mathrm{C}$ & -12 & -12 & -13 & -13 \\
\hline Цетановое число & ед. & 50,2 & 50,9 & 52,4 & 53,3 \\
\hline $\begin{array}{l}\text { Диаметр пятна } \\
\text { износа }\end{array}$ & мКм & 612 & 240 & 200 & 180 \\
\hline
\end{tabular}

Проведённые исследования окислительной стабильности дизельного топлива со сложным эфиром ДТМ и ЖКРМ без стабилизации его амидоимидазолином показали значительное ухудшение его окислительной стабильности. Стабилизированный сложный эфир показал окислительную стабильность на уровне дизельного топлива. Введение стабилизированных эфиров в качестве полифункциональной присадки в дизельное топливо значительно улучшает его смазывающие свойства, а также увеличивает цетановое число до требуемых показателей (рисунок 1). 


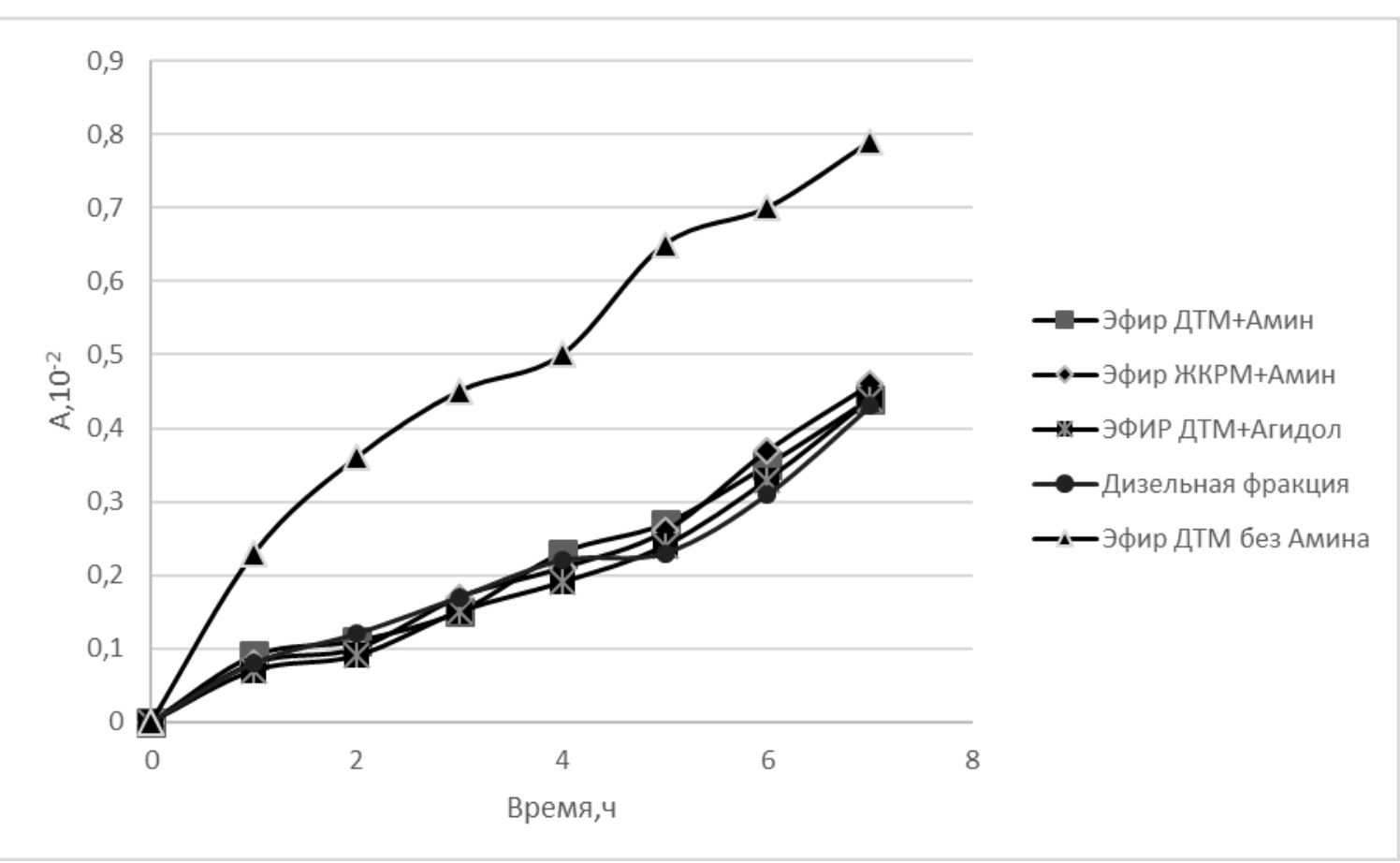

Рисунок 1. График изменения окислительной стабильности топлива с объёмным содержанием в дизельном топливе 1,5 \% массовых эфирных присадок

\section{Вывод}

Таким образом, разработан удобный метод синтеза полифункциональной присадки на основе сложных эфиров ДТМ и ЖКРМ этиленгликолем с применением вакуумного насоса и последующим вовлечением непрореагировавших в реакцию этерификации жирных кислот ДТМ и ЖКРМ с амидо-имидазолиновыми добавками для придания присадке противоокислительных свойств [4].

\section{Список используемых источников}

1. Быченин А.П. Повышение ресурса плунжерных пар топливного насоса высокого давления тракторных дизелей применением смесевого минеральнорастительного топлива: дис. ... канд. техн. наук. Пенза, 2007. 184 с.

2. Wei D.P. The Lubricity of Fuels I. Wear Studies on Diesel Fuel Components // Acta Petrolei Sinica. 1986. No. 2. P. 79-87.

3. Wei D.P. The Lubricity of Fuels II. Wear Studies Using Model Compounds // Acta Petrolei Sinica. 1990. No. 4. P. 90-105. 
4. Пат. 2723116 РФ, МПК С 10 L 1/224. Противоизносная присадка к дизельному топливу с ультранизким содержанием серы / Н.К. Кондрашова, А.М. Еремеева, С.Я. Нелькенбаум, К.С. Нелькенбаум. 2019131789, Заявлено 08.10.2019; Опубл. 08.06.2020. Бюл. 16.

\section{References}

1. Bychenin A.P. Povyshenie resursa plunzhernykh par toplivnogo nasosa vysokogo davleniya traktornykh dizelei primeneniem smesevogo mineral'norastitel'nogo topliva: dis. kand. tekhn. nauk [Increasing the Service Life of the Plunger Pairs of the High-Pressure Fuel Pump of Tractor Diesel Engines by Using a Mixed Mineral-Vegetable Fuel: Cand. Engin. Sci. Diss.]. Penza, 2007. 184 p. [in Russian].

2. Wei D.P. The Lubricity of Fuels I. Wear Studies on Diesel Fuel Components. Acta Petrolei Sinica, 1986, No. 2, pp. 79-87.

3. Wei D.P. The Lubricity of Fuels II. Wear Studies Using Model Compounds. Acta Petrolei Sinica, 1990, No. 4, pp. 90-105.

4. Kondrashova N.K., Eremeeva A.M., Nelkenbaum S.Ya., Nelkenbaum K.S. Protivoiznosnaya prisadka $k$ dizel'nomu toplivu s ul'tranizkim soderzhaniem sery [Ultra Low Sulfur Diesel Antiwear Additive]. Patent RF, No. 2723116, 2020. [in Russian].

\section{Сведения об авторах}

\section{About the authors}

Ахметов Арслан Фаритович, доктор технических наук, профессор, заведующий кафедрой «Технология нефти и газа», УГНТУ, г. Уфа, Российская Федерация

Arslan F. Akhmetov, Doctor of Engineering Sciences, Professor, Head of Oil and Gas Technology Department, USPTU, Ufa, Russian Federation e-mail: tngrusoil@mail.ru 
Халилов Леонард Мухибович, доктор химических наук, профессор, заведующий лабораторией структурной химии, Институт нефтехимии и катализа Российской академии наук, г. Уфа, Российская Федерация

Leonard M. Khalilov, Doctor of Chemical Sciences, Professor, Head of Structural Chemistry Laboratory, Institute of Petrochemistry and Catalysis of Russian Academy of Sciences, Ufa, Russian Federation

e-mail: khalilovlm@gmail.com

Баулин Олег Александрович, канд. техн. наук, доцент, ректор, УГНТУ, г. Уфа, Российская Федерация

Oleg A. Baulin, Candidate of Engineering Sciences, Associate Professor, Rector, USPTU, Ufa, Russian Federation

e-mail:info@rusoil.net

Нелькенбаум Савелий Яковлевич, директор ООО «Синтез ТНП», г. Уфа, Российская Федерация

Savely Ya. Nelkenbaum, Director of Sintez TNP LLC, Ufa, Russian Federation

e-mail: sale@ sintez-tnp.ru

Нелькенбаум Константин Савельевич, соискатель ученой степени кандидата технических наук кафедры «Технология нефти и газа», УГНТУ, технолог ООО «Синтез ТНП», г. Уфа, Российская Федерация

Konstantin S. Nelkenbaum, Applicant at Oil and Gas Technology Department, USPTU, Technologist of Sintez TNP LLC, Ufa, Russian Federation e-mail: fox@web-rb.ru 